\title{
Paired tumor biopsy analysis and safety data from a pilot study evaluating Tremelimumab - a monoclonal antibody against CTLA-4 - in combination with ablative therapy in patients with hepatocellular carcinoma (HCC)
}

\author{
Austin Duffy ${ }^{1 *}$, Sid P Kerkar ${ }^{2}$, David E Kleiner ${ }^{1}$, Susanna Ulahannan ${ }^{3}$, Metin Kurtoglu³ ${ }^{3}$ Oxana Rusher ${ }^{3}$, \\ Suzanne Fioravanti ${ }^{3}$, Melissa Walker ${ }^{3}$, William D Figg ${ }^{4}$, Kathryn Compton ${ }^{4}$, Aradhana Venkatesan $^{5}$, \\ Nadine Abi-Jaoudeh ${ }^{5}$, Brad Wood ${ }^{5}$, Tim F Greten ${ }^{3}$
}

From Society for Immunotherapy of Cancer 29th Annual Meeting

National Harbor, MD, USA. 6-9 November 2014

\section{Background}

Tremelimumab is a fully human monoclonal antibody that binds to CTLA-4 expressed on the surface of activated $\mathrm{T}$ lymphocytes and results in inhibition of B7CTLA-4-mediated down regulation of $\mathrm{T}$ cell activation. Both transcatheter arterial chemoembolization (TACE) and radiofrequency ablation (RFA) have been shown to induce a peripheral immune response which may enhance the effect of anti-CTLA4 treatment in patients with advanced HCC.

\section{Methods}

Patients with HCC (Childs Pugh A/B7; Barcelona Clinic Liver Cancer Stage C; ECOG 0/1; previously progressed on Sorafenib) are being enrolled in a pilot study of Tremelimumab at 2 dose levels (DL1 and DL2) until disease progression (irRECIST). Subtotal TACE or RFA is performed during study week 6 with DLT evaluation period encompassing first 8 weeks of study. Tumor tissue is collected for analysis at baseline on all patients with optional on-treatment tumor biopsies performed at the time of the radiologic procedure.

\section{Results}

11 pts have been treated so far, 6 pts at DL1 and 5 pts at DL2; M:F 9:2; Median age $=54($ range 42-75);

${ }^{1}$ National Cancer Institute, National Institutes of Health, Bethesda, MD, USA Full list of author information is available at the end of the article
Cirrhosis present in 7pts. Hepatitis B/C/neg: 3/6/2. 4 pts received TACE, 7 underwent RFA during week 6 of Tremelimumab therapy. Tumor tissue is being collected for analysis at baseline in all patients. Once DL1 was established as safe and feasible on-treatment tumor biopsies are being performed at the time of the radiologic procedure (Day $36+/$ - 96hrs) on all patients. So far 2 of 5 patients treated at DL2 have shown extensive immune cell infiltration on tumor biopsies after 6 weeks of Tremelimumab. More in depth analysis are currently being conducted and will be presented together with safety data.

\section{Conclusions}

Tremelimumab in combination with TACE or RFA in patients with advanced HCC is feasible. Preliminary pathology data will be presented regarding all post-treatment tumor biopsies.

\begin{abstract}
Authors' details
'National Cancer Institute, National Institutes of Health, Bethesda, MD, USA. ¿2aboratory of Pathology, Center for Cancer Research, National Cancer Institute, National Institutes of Health, Bethesda, MD, USA. ${ }^{3}$ Gastrointestinal Malignancies Section, Center for Cancer Research, National Cancer Institute, National Institutes of Health, Bethesda, MD, USA. ${ }^{4}$ Clinical Pharmacology Program, Center for Cancer Research, National Cancer Institute, National Institutes of Health, Bethesda, MD, USA. ${ }^{5}$ Radiology and Imaging Sciences, Center for Cancer Research, National Institutes of Health, Bethesda, MD, USA.
\end{abstract}

Published: 6 November 2014 
doi:10.1186/2051-1426-2-S3-P98

Cite this article as: Duffy et al:: Paired tumor biopsy analysis and safety data from a pilot study evaluating Tremelimumab - a monoclonal antibody against CTLA-4 - in combination with ablative therapy in patients with hepatocellular carcinoma (HCC). Journal for ImmunoTherapy of Cancer 2014 2(Suppl 3):P98.

Submit your next manuscript to BioMed Central and take full advantage of:

- Convenient online submission

- Thorough peer review

- No space constraints or color figure charges

- Immediate publication on acceptance

- Inclusion in PubMed, CAS, Scopus and Google Scholar

- Research which is freely available for redistribution

Submit your manuscript at www.biomedcentral.com/submit 